\section{Anotações sobre a análise crítica de discurso em pesquisas qualitativas no campo da saúde}

\section{Notes on the critical analysis of discourse in qualitative studies in the field of health}

Maria Lúcia Magalhães Bosi 1

Marcos Aurélio Macedo 2
1 Universidade Federal do Ceará Avenida da Universidade, 2853. Benfica. Fortaleza, CE, Brasil. CEP. 60.020-181.

E-mail: malubosi@ufc.br

2 Universidade Estadual do Vale do Acaraú. Sobral, CE, Brasil.

\begin{abstract}
The emergence of health systems based on a broadened concept of health that questions the understanding of actions in the field of health capable of bringing together structure and subject has led to the development of evaluative studies as a mode of investigation and in particular methodological proposals guided by a qualitative focus in the study of human health. Qualitative research involves qualitative epistemology, a tradition composed of numerous currents derived from various paradigms and fields, which lack in-depth study, in terms of revealing the ontological, epistemological and, by extension, methodological basis of each, including an operational plan. Such undertakings are still very rare in the specialized literature on the subject, as is clear from the predominance of empirical studies in publications and the notable scarcity of epistemological, theoretical and methodological discussions regarding operationalized evaluative models. In view of this, the present article aims to highlight a number of conceptual elements inherent in analysis, understood as a central epistemological stage in a (critical) interpretative focus. The text then focuses on one specific school of thought - Critical Discourse Analysis - with a view to recovering some fundamental features and registering operational aspects that have been employed in qualitative studies in the field of health. Key words Research methodology, Qualitative health research, Public health
\end{abstract}

\section{Resumo}

A emergência de sistemas de saúde ancorados em uma concepção ampliada de saúde, pressupondo, em seu ideário, dimensões que interrogam a compreensão das ações nesse campo capazes de articular estrutura e sujeito, vem impulsionando pesquisas avaliativas como modalidade de investigação, notadamente propostas metodológicas orientadas pelo enfoque qualitativo. Falar em pesquisa qualitativa é aludir à epistemologia qualitativa, tradição composta por numerosas vertentes, oriundas de paradigmas e campos disciplinares diversos, que carecem de aprofundamento, na perspectiva de desvelar, para cada uma delas, sua vinculação ontológica, epistemológica e, por extensão metodológica, incluindo o plano operacional. Tal empreendimento ainda é muito escasso na literatura especializada sobre o tema, verificando-se nas publicações o predomínio de estudos empíricos, convivendo com uma notável escassez de discussões epistemológicas e teórico-metodológicas atinentes aos modelos avaliativos operacionalizados. Ante essa configuração, este artigo se propõe a colocar em relevo alguns elementos conceituais inerentes à análise, entendida como etapa epistemológica central no enfoque (crítico) interpretativo. Na sequência, o texto focaliza uma vertente específica - a Análise Crítica do Discurso - com o intuito de recuperar alguns fundamentos e registrar aspectos operacionais que vimos empregando em pesquisas qualitativas em saúde.

Palavras-chave Metodologia de pesquisa, Pesquisa qualitativa em saúde, Saúde coletiva 


\section{Introdução}

Nos últimos anos, a produção científica atinente ao enfoque qualitativo de investigação em saúde tem experimentado notável crescimento, especialmente nas questões referentes ao cuidado, com especial destaque para sua dimensão subjetiva, ou seja, o plano dos significados e sentidos construídos no processo. Tal cenário decorre, dentre outros aspectos, da emergência de sistemas de saúde ancorados em uma noção ampliada de saúde, pressupondo a humanização, a integralidade e o controle social das práticas, dimensões essas que estimulam a compreensão da saúde articulando estrutura e sujeito. No Brasil, a vigência do Sistema Único de Saúde (SUS) - com seu arcabouço jurídico e éticopolítico expressos em diretrizes, princípios e ideário originalmente propostos pelo movimento de reforma sanitária iniciada nos anos 1980, bem como a existência concreta de seus desdobramentos e estratégias, a exemplo da Estratégia Saúde da Família (ESF), são circunstâncias que ilustram o impulso dado à avaliação de componentes específicos. $1-3$

Nesse escopo se evidencia a expansão da pesquisa qualitativa como modalidade de investigação na saúde, notadamente a idealização de propostas metodológicas voltadas à subjetividade inerente à produção e utilização das práticas em saúde, inscrevendo-se no que aqui se demarca como pesquisa avaliativa qualitativa.4-9 A propósito desse termo, Uchimura e Bosi 10 advertem sobre algumas dificuldades na utilização do conceito qualidade, dando origem a novos construtos, distintas definições e "tensões semânticas" presentes nas definições deste termo na literatura, consoante o que a mesma fonte define como multidimensionalidade intrínseca e extrínseca, possibilitando polarizações.

Tal polissemia exige rigorosa demarcação ao se empregar o termo qualitativo, uma vez que, nesse campo específico, o paradigma hegemônico privilegia dimensões objetiváveis (no sentido do que pode ser quantificado), resultando na exclusão da dimensão subjetiva, simbólica, ou seja, o propriamente humano. Portanto, ainda que possa ser tomada como componente da qualidade, ao nos referirmos à pesquisa qualitativa de políticas, programas, serviços ou ações em saúde, referimo-nos àquela que necessariamente inclui os atores envolvidos nas ações em saúde, especialmente a produção intersubjetiva (valores, sentimentos e desejos), plano não passível de apreensão por instrumentos estruturados. Do exposto se depreende que falar em pesquisa qualitativa é aludir à epistemologia qualitativa, tradição composta por numerosas vertentes oriundas de paradigmas e campos disciplinares diversos, que carecem de aprofundamento, desvelando, para cada vertente, sua vinculação ontológica, epistemológica e, por extensão metodológica, incluindo o plano operacional. Tal empreendimento ainda é muito escasso na literatura especializada sobre o tema, verificando-se nas publicações, o predomínio de estudos empíricos,11-13 ao lado da escassez de discussões epistemológicas e teórico-metodológicas. Quanto à "epistemologia qualitativa", essa terminologia é aqui empregada como sinônimo de teoria do conhecimento, marcando distância de entendimentos que operam um efeito de redução semântica, convertendo-a em mera vertente metodológica. Refere-se assim à reflexão sobre a natureza do ato de conhecer e produzir enunciados, posição que vai ao encontro do que se encontra diluído na obra de Bohman, 14 em favor do abandono de uma Epistemologia com "E", dando lugar a epistemologias com "e" (empiricistas, racionalistas, qualitativas, etc), das quais retiram as bases que justificam suas diferentes metodologias. Assim, o que se inclui sob o rótulo abrangente de epistemologia qualitativa, abrange um extenso conjunto de approaches em pesquisa social, que compartilham alguns pressupostos ou uma "postura", ou seja, "um fundamento epistemológico com base no qual as técnicas façam sentido - um método - e do qual as mesmas se originem [...] (para tanto) [...] é imprescindível levar em conta: a) a natureza da pergunta ou objetivo da investigação; b) uma determinada postura teórica [...]; c) a correspondente estratégia para a obtenção de informações e sua análise". Aos nos referirmos à epistemologia qualitativa, muito sinteticamente, fazemos alusão a esse conjunto de elementos, considerados sinergicamente15 (p. 33-34).

Ante essa configuração, este artigo se propõe a colocar em relevo alguns elementos conceituais, inerentes à análise na tradição qualitativa, entendida como etapa epistemológica central no enfoque (crítico) interpretativo, focalizando, na sequência, uma vertente específica - a Análise Crítica do Discurso (ACD) - com o intuito de recuperar alguns fundamentos e registrar aspectos operacionais em pesquisas qualitativas em saúde orientadas por essa vertente.

\section{O desafio da análise no enfoque crítico interpretativo de pesquisa}

A análise do material qualitativo, seja qual for a vertente analítica, longe de representar o desfecho de procedimentos meramente técnicos ou instrumen- 
tais, constitui-se como um desafio que envolve operações epistemológicas sofisticadas. Ante a complexidade e vicissitudes do ato compreensivo, tal labor científico requer competência e rigor intelectual, traduzidos em fundamentação epistemológica e metodológica, abertura ao diálogo acadêmico e, em especial, criatividade e reflexivi$\operatorname{dade}^{16}$ (p. 16-18).

Articulação do pensamento por tal sentido compreensivo incorpora, ainda, a ousadia de combinar rigor científico a um conjunto de habilidades inerentes às múltiplas dimensões da análise, tais como a artística, a intuitiva e a dialógica, muitas vezes exercitadas, mas nem sempre explicitadas, do modo exigido na reflexividade científica sustentada por Bourdieu 17 (p. 694). Sendo assim, impõe-se um esforço hermenêutico audacioso que não se coaduna, como assevera Bosi, com uma mera "aventura"18 (p. 580) ou, ainda, apegos ideológicos.

Nesse sentido, cabe recuperar a advertência de Paillé e Mucchielli, 19 quando analisam a estreita conexão do momento de análise (que estendemos às demais etapas) com a congruência ontoepistemológica das pesquisas:

\footnotetext{
Des choix épistémologiques, theóriques et méthodologiques soustendent toutes les composantes d'une enquête. Ainsi, pourquoi examiner un materiau de recheche, jusqu'à quel point, avec quelles attentes, dans quel but, avec quel objectif, de quelle manière [...] sous quel angle, pour quel public?[...] qu'y a-t-il derrière cette attitude, cette émotion, ce sentiment, [...] en lien avec la situation étudiée? Pourquoi interpeller ce modèle, privilégier cet angle, em appeler à cet element théorique en vue de la situation à analyser? (op cit, p. 119)
}

Diante da diversidade de dimensões analíticas envolvidas em pesquisas nessa modalidade, a triangulação de métodos (e técnicas correlatas) ${ }^{16,20}$ na perspectiva de uma estratégia de diálogo interdisciplinar revela-se como um elemento promissor. Para tanto, nos empreendimentos analíticos acerca de programas e serviços de saúde, cabe valorizar o entrelaçamento entre o(s) discurso(s) dos vários segmentos, sobretudo o discurso estatal, expresso em documentos oficiais, com outros textos e seus desdobramentos no contexto envolvido, considerando com primazia o ponto de vista dos beneficiários/usuários, em contraste com a linguagem técnica dos documentos oficiais.

Adicionalmente, ainda inspirados nos pressupostos teórico-metodológicos de Coffey e Atkinson16 (p. 17-19), cumpre assinalar que a combinação de diferentes técnicas de investigação, a exemplo da triangulação de métodos, como acima aludido, é coerente com a complexidade da compreensão, posto que a análise do material construído (já que, em um enfoque crítico não cabe dizer "dados") a partir de distintos ângulos favorece o desvelamento - ou a construção, como advertem os mesmos autores - da realidade estudada.

Partimos da consideração de que são tensas e complexas as relações entre o informalismo da linguagem do senso comum e o formalismo da linguagem técnica, especialmente a jurídico-estatal, sobretudo porque essa última se reveste de uma função instrumental na retórica institucional dos agentes políticos21 (p. 34-35). Esta não raro estranha, distanciada, ou mesmo oposta aos anseios populares, a exemplo das demandas comumente manifestas no discurso de usuários ou beneficiários de uma política social, demanda uma análise crítica para seu desvelamento. Consoante Maudidier et al.22 (p. 64-65), faz-se necessário um esforço adicional, um "para além da linguística da língua".

A constituição de uma linguagem do discurso se inscreve na história [...]. Nascida de horizontes diversos esta linguística do discurso procura ir além dos limites que se impôs uma linguística da língua, fechada dentro do estudo do sistema. Ultrapassando os limites da frase, considerada como o nível último da análise na combinatória estruturalista, esforço para escapar da dupla redução da linguagem à língua, objeto ideologicamente neutro, e ao código, com função puramente informativa; tentativa de reintroduzir o sujeito e a situação de comunicação excluídos em virtude do postulado da imanência, esta linguística do discurso se confrontou com o problema do extralinguístico. (opcit, p. 64-65)

Outrossim, desvela-se a dimensão artística, de experimentação inerente à análise nessa tradição, sem com isso, subtrairmos o estatuto científico, visão que repetiria a cisão operada pelo pensamento moderno. Sobre arte e ciência, pode-se traçar um paralelo entre fins e meios distintivos dos domínios de atuação de artistas e cientistas, conforme representados em notável síntese de Kuhn²3 (p. 264).

$\mathrm{O}$ cientista, à semelhança do artista, é orientado por considerações estéticas e guiado por modos estabelecidos de percepção. (...) O que quer que signifique o termo 'estética', o objetivo do artista é a produção de objetos estéticos, os enigmas técnicos são o que eles têm de resolver a fim de produzir esses objetos. Para os cientistas, os enigmas técnicos resolvidos são o objetivo, e a estética é um instrumento para sua consecução. Quer no domínio das produções, quer no das atividades, os fins 
dos artistas são os meios dos cientistas e vice-versa (grifos nossos)

No que concerne ao lugar que a subjetividade humana ocupa no trabalho interpretativo, preferimos nesse processo hermenêutico, que também é de autoconhecimento, a estranheza do processo de revelação, suposto por Heidegger24 (p. 251), pelo qual o sujeito ganha existência, mediada pela palavra em seu sentido mais fundo. Faz-se necessário, para compreender a "realidade" humana, interpretar o mundo; nisso, a linguagem e sua "decifração" processo eminentemente subjetivo - tem inegável importância, cabendo inserir a subjetividade na materialidade a que se refere. Ademais, como esclarece Dilthey25 (p. 126), a vida não nos é dada imediatamente, mas com a intermediação do pensamento, na qual cada visão de mundo tem seu caráter histórico e, ao mesmo tempo, se articula com a historicidade propriamente dita de seu movimento dialético.

Aqui, cabe recuperar que a fidedignidade da investigação qualitativa no sentido de representação coerente da realidade, é uma questão sensível, e vem sendo objeto de recorrentes questionamentos, internos e externos ao campo Saúde Coletiva. Os paradigma positivista e pós-positivista, não raro, cobram dessa tradição: precisão, exatidão e propriedades de generalização, como se congruentes fossem com os planos ontológico e epistemológico a que se referem. Nesse contexto de disputas, em especial, no âmbito da saúde pública, acreditamos que importa buscar sistemas abertos de pesquisa, e nesse sentido, conforme prelecionam Lüdke e André26 "manter uma atitude reflexiva e aberta, admitindo-se que outras interpretações possam ser sugeridas, discutidas e igualmente aceitas" (p. 52).

Com efeito, a linguagem condiciona o nosso pensamento, ao mesmo tempo em que constitui meio para representar a realidade e, além disso, se apresenta (na perspectiva do conhecimento) como um elemento "formativo de realidades" 27 (p. 21-22). Por sua vez, "as relações de linguagem são relações de sujeitos e de sentidos e seus efeitos são múltiplos e variados. Daí uma definição de discurso ser o "efeito de sentidos entre locutores" 28 (p. 21). Nesse prisma, têm-se diversas dimensões e possibilidades interpretativas, em face das quais cumpre ao intérprete - em face da tensão dialética existente entre a familiaridade e do caráter estranho da mensagem que nos é transmitida pela tradição - decodificar a palavra, nomeando-a, interpenetrando criador e criatura por fusão de horizontes 29 (p. 67-69).

Nesse ponto, é oportuno citar Bouveresse 30 (p.
121-124), que ao tempo de sua resignação contra o abuso do cientificismo em sua pretensão totalizante, denuncia outra forma de poder, agora tipificado em uma forma de literarismo, pautado na premissa positivista de que o dito pela ciência passa a ser interessante e profundo quando transcrito para uma linguagem literária permeada pelo sentido conotativo. A ideia de conhecimento metafórico indica uma relação com componentes da realidade concreta ou objetiva (fora do ser), da qual não se tem propriamente controle 31 (p. 42-47). Ademais, por força da capacidade de acesso à dimensão simbólica, o discurso e as metáforas nele manifestas cumprem o papel de conduzir o pesquisador à compreensão de construções sociais pertinentes às racionalizações, às representações, às normas e aos valores. 32 Nesse caminho, no âmbito da análise qualitativa, procurar as estruturas metafóricas que trazem significados não literais constitui um caminho para chegar à compreensão do não dito quando se expressa algo. 29

Interessante mencionar ainda o movimento sensacionista por alusão à poética de Fernando Pessoa e à ideia de que não existe a realidade em si, mas somente sensações (conscientes na arte) do que seja realidade 33 (p. 1). Assim, a própria compreensão deve ser explorada por conjugações e implicações com antíteses fundamentais do conhecimento: subjetivo/objetivo, espiritual/material, interior/exterior. Desse modo, mediado pela palavra, assume-se uma sutil tensão dialética dos contrários no ato propriamente humano de compreender, processo esse que no âmbito da tradição hermenêutica requer disciplina.

A propósito, o termo disciplina, conforme ensina Coffey e Atkinson, 16 traz em si conotação de rigor e cuidado, não se confundindo, em absoluto, com "castigo", resiliência ou oposição à criatividade. Para os mesmos autores, a partir de tal premissa basilar de análise do material qualitativo, deve o pesquisador sustentar a consistência dos procedimentos analíticos, com abertura para reflexão do tipo: "É possível ganhar muito quando se ensaiam diferentes ângulos analíticos [...]. Se geram novas luzes, e às vezes uma e outra pode escapar das perspectivas analíticas que se tornaram estereotipadas e estéreis" (opcit, p. 16).

A Hermenêutica de Profundidade (HP) ${ }^{34}$ constitui um referencial metodológico de interesse para a ACD tendo em vista que prioriza o estudo da produção de sentido e recomenda que o intérprete deva ater-se às formas simbólicas produzidas por sujeitos e reconhecidas pelos próprios na qualidade de construções significativas, originárias do pensamento, desvenda o que não está explicitamente 
presente.

Nessa arte, uma vez assumida a pretensão de aproximação com o que pré-compreendemos existir de verossímil no fenômeno em estudo, acreditamos que a técnica de interpretação/reinterpretação da linguagem, última etapa de uma HP34 (p. 475-477) tensiona a pré-compreensão junto à abertura para transformação ao conhecer em essência (profundamente) a realidade em estudo, uma vez identificada sua relação dialética, indo e vindo, trajetória essa conhecida como círculo hermenêutico 29 (p. 58), justamente por propor a dialeticidade entre partes e o todo, em um arranjo de confirmações e negações a todo tempo. Tal premissa garante a possibilidade de avançar a teoria e não somente confirmá-la mediante os "dados".

Nesse giro argumentativo, é pertinente destacar que a codificação da informação qualitativa - ao exigir a leitura e releitura e realizar uma série de ações que ajudam na seleção, recorte, fragmentação e categorização - possibilita ao investigador obter uma visão (recontextualizada) em perspectiva do conjunto de informações reunidas. Nada obstante, a interpretação requer transcender os dados "fáticos" como parte de um processo analítico norteado por zelo e rigor. ${ }^{4}$ Rigor que pressupõe alinhamento, ou seja congruência entre paradigmas, marcos teóricometodológicos e técnicas de pesquisa - tema considerado como um dos desafios ainda potentes no âmbito da tradição qualitativa 8,18 , incidindo sobre a pesquisa avaliativa sob esse enfoque.

Contudo a codificação, como parte do processo compreensivo, é um procedimento multifacético que requer um elaborado esforço criativo e consistente embasamento teórico, ambos implicados com o sujeito epistêmico investido da tarefa de investigador-mediador, atento à diversidade semântica que emerge do universo empírico através de recursos linguísticos.

Na perspectiva de uma análise crítica, ou críticointerpretativa, tal como aprofundaremos a seguir, o discurso - uma vez reconhecido como prática social (nas dimensões reprodutiva e construtiva) - deriva da interface dialética entre estruturas e relações sociais. Sob essa óptica, a análise de discurso abrange também algumas dimensões implicadas com o contexto de quem fala em um dado tempo e lugar. 35,36 Sendo assim, em pesquisas concretas, importa conhecer a representação dos processos comunicativos implicados com a condição material, particularmente do modo expressado (e apreendidos como códigos no esforço hermenêutico) pelos participantes do estudo.

\section{Análise crítica do discurso como vertente metodológica}

Curso é a forma arcaica do particípio do verbo correr, dis é prefixo que indica "em todas as direções", portanto, etimologicamente, discurso significa correr em todas as direções 28 (p.15), 37 (p.229) sustentando a ideia central, já antes aludida, da inesgotabilidade dos sentidos ou significados presentes em uma enunciação discursiva. Por outro lado, o discurso como objeto de análise é uma ideia originária da produção intelectual de Pêcheux,38-40 na França dos anos 1960-1970, que não tardou a se destacar como espaço de articulação teórica e método: a Análise de Discurso (AD).

Em sua nascente trajetória, a AD se desenvolveu a partir da convergência e interfaces de três campos distintos do conhecimento, quais sejam: a) a linguística - interrogando a historicidade por ela negligenciada; b) o materialismo - questionando a ausência do simbólico; e c) a psicanálise - reconhecendo a ideologia e a historicidade a ela inerente como materialidade implicada ao inconsciente 28 (p. 20). Logo surgiu uma diversidade de vertentes teóricometodológicas e também distintas posturas interpretativas, em parte decorrentes das múltiplas relações interdisciplinares voltadas à questão da linguagem e sua compreensão22 (p. 67). Focalizaremos aqui, abertos a controvérsias, uma atitude reflexiva e hermenêutica implicada com o que, com amparo na literatura, circunscrevemos como Análise Crítica do Discurso.

Sem se fixar nos originais de Fairclough, 36 pesquisador da Universidade de Lancaster e primeiro a usar o termo, no texto intitulado Critical and Descriptive Goals in Discourse Analysis, 36 publicado em 1985, cabe reconhecer que, em português (e também no idioma espanhol), conforme amplamente reconhecido, a expressão Critical Discourse analysis foi traduzida tanto como "análise crítica do discurso" quanto "análise de discurso crítica", conforme comentado em vários textos, dentre eles, os de Melo, 41 Tílio, 42 e Guimarães. ${ }^{43}$ Podemos ainda citar o uso dessa terminologia nas traduções da obra de Van Dijk 44 - a exemplo de El análisis critico del discurso - autor esse que, ao lado de Fairclough 35,36 e Wodak, ${ }^{45}$ figuram como referência central nessa tradição.

Ainda na perspectiva da produção francesa, cabe destacar que também se deve a Pecheux 46 (p. 21-23) a adjetivação de crítica à análise de discurso com fundamento na dinâmica desse na transformação criativa e na reprodução de ideologias. Nessa construção analítica - sustentada na tradição teórica 
da Escola de Frankfurt (sobretudo nas contestações filosóficas de Louis Althusser) - aquele filósofo francês teria se baseado na combinação de uma teoria marxista do discurso com métodos linguísticos de análise textual, distanciado-se desse modo do estruturalismo e de outras perspectivas teóricas que negam a contextualização/dinâmica histórica da língua, por considerá-la um sistema (ou uma "estrutura") unitário e fixo 35 (p. 58-59).

Para exemplificar, o generativismo, consoante o mesmo autor, oferece um modelo lógico-matemático com vistas a retratar a língua como mera estrutura fundada em princípios e regras universais para orientar a produção de textos. ${ }^{35}$ Sendo assim, essa última teoria linguística é incapaz de subsidiar o desvelamento de distintas dimensões discursivas, eventualmente presentes no universo simbólico de um serviço de saúde, identificadas com categorias como contradição, reificação, oposicionalidade e mediação. $46-48$

$\mathrm{Na}$ articulação compreensiva que envolve a práxis da pesquisa qualitativa em saúde, uma vez consideradas distintas dimensões analíticas no contexto do universo empírico investigado, é necessário conhecer a conexão entre diferentes manifestações do pensamento a partir do estudo da intertextualidade e da interdiscursividade presente, por exemplo, no confronto entre o regulamento de um programa e na opinião de um seu beneficiário, possibilitando, assim, refletir acerca do potencial dialógico do discurso como materialidade sóciohistórica, focalizando a ideologia como dimensão de análise:

\footnotetext{
O funcionamento da ideologia em geral como interpelação dos indivíduos em sujeitos (e especificamente em sujeitos de seus discursos) se realiza através do complexo das formações ideológicas e fornece a "cada sujeito" sua "realidade" enquanto sistema de evidências percebidas aceitas - experimentadas. 35 (p. 149).
}

O emprego do termo discurso, como proposto por Fairclough, 35 deve ainda reconhecer que a linguagem representa uma prática social, inscrita no cotidiano das experiências de vida, na materialidade histórica do sujeito implicado com a sua própria existência social. Nessa acepção, conforme o mesmo autor, há diversas implicações com o mundo vivido, com destaque a ideia de que "o discurso é socialmente construído,(...) não apenas da representação do mundo, mas de significação do mundo, constituindo e construindo o mundo em significado" (p. 91). Nesse sentido, envolve a ideia de um devir histórico (em oposição ao mecanicamente dado): o homem transformando-se no compasso das mudanças das relações sociais, compondo uma unidade dialética e não formal48 (p.14-17).

A ACD, aqui tomada como vertente analítica em pesquisas avaliativas, se inscreve na convergência das tradições crítica e interpretativa, retendo em seus fundamentos aqueles apontados por autores como Orlandi, ${ }^{28}$ Gadamer, ${ }^{29}$ Fairclough, 35,36 Thompson, 34 Coffey e Atkinson, ${ }^{16}$ além dos autores seminais já comentados, permitindo explorar a dimensão social e outras implicações contextuais do discurso.

Nas aproximações à análise de discursos, em pesquisas qualitativas, impõe-se uma atitude críticoreflexiva que atravessa a noção de indivíduo social sustentada no marxismo, na direção de perspectivas que considerem a dialética da vida social47 (p. 6972) e possibilidades de mudanças paradigmáticas 49 (p. 117). Nesse passo, adotando a premissa gadameriana da consciência histórica29 (p. 70-71), nos remetemos ao simbólico demarcado em teorias que se debruçam sobre a subjetividade, por vezes, minimizada pelo materialismo histórico, operando um deslocamento da concepção de indivíduo/classe para a de sujeito/pessoa. Cabe ainda rever o modo como se concebe a ideologia e a comunicação a ela implicada na base das relações do poder hegemônico, inclusive os vieses da dominação por trás das representações de interesses que atribuem significado às coisas como "verdade". Todavia essa última não existe fora do poder ou sem ele; cada sociedade desenvolve e sanciona modalidades de discursos verdadeiros e mecanismos distintivos dos enunciados falsos, valorizando o modo de dizer o que deve funcionar como verdade 50 :

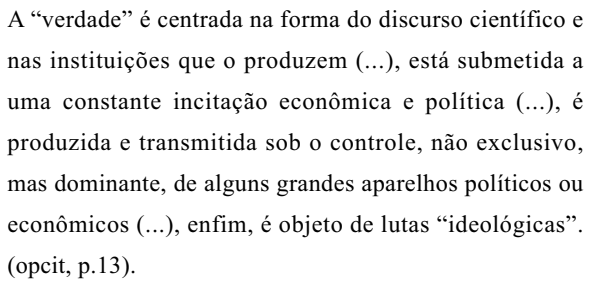

Assim, na busca da compreensão da constituição do sujeito, em função das ideologias que o implicam no âmbito de suas funções e relações sociais, particularmente aquelas associadas à sua inserção como beneficiários/usuários de ações públicas, segmentos tantas vezes inseridos como participantes em pesquisas qualitativas em saúde, torna-se estratégico adotar uma versão analítica de discurso de inspiração crítica identificada com o acontecer histórico. Por tal enfoque reflexivo, cabe valorizar a vertente interpretativa que considera as produções discur- 
sivas na qualidade de componentes de formações ideológicas - contexto no qual o sujeito que fala toma posição em meio às representações das quais ele é o suporte em um determinando momento histórico's (p. 107-109). Dito de outra forma, as narrativas individuais estão situadas dentro de interações particulares e no interior de discursos sociais específicos.

Do exposto se depreende que operacionalizar a ACD no âmbito de pesquisas qualitativas em saúde, mais que construir um discurso alternativo ou avaliar os resultados "práticos" da implementação de políticas, programas ou serviços em saúde, permite analisar tanto a estrutura como a dinâmica de diferentes discursos (ou práticas discursivas) nesse campo 44 - os elementos com que operam; as lutas entre os mesmos; os diferentes interesses e os complexos mecanismos que possibilitam a hegemonia (no sentido gramsciano) ${ }^{48}$ de certos discursos sobre outros, identificando também as contradições e resistências. Retomando Fairclough 35 (p. 22), "qualquer evento discursivo é considerado simultaneamente um texto, um exemplo de prática discursiva e um exemplo de prática social", o que justifica sua proposição voltada a um modelo analítico dimensional que possa considerar essa complexa dinâmica. Para tanto, e visando a aportar elementos que subsidiem o desenrolar das análises em pesquisas empíricas, comentamos na sequência dois momentos centrais nessa abordagem.

\section{Sobre os processos de codificação e de} categorização: subsídios operacionais

$\mathrm{Na}$ perspectiva que adotamos o trabalho com as informações qualitativas envolve tratamento dos componentes mais significativos do materia empírico, mediante algumas operações raramente explicitadas em publicações, voltadas, em sua maioria, para os resultados e, quando muito, detendo-se nos principais fundamentos do enfoque. Neste tópico, pretendemos oferecer alguns subsídios direcionados a essa lacuna, sem a pretensão de sermos prescritivos ou de restringir o entendimento da etapa analítica como um sistema aberto. 13 Contudo, acreditamos que percorrer algumas etapas de operacionalização da ACD pode servir como ilustração, sobretudo para pesquisadores iniciantes nesse enfoque.

No trato das entrevistas, conduzidas de forma não-diretiva $\mathrm{e}$, portanto, dialógica, tomamos o cuidado de transcrevê-las logo após a sua realização, ainda com a memória recente das impressões de maior impacto em nosso entendimento. Utilizando ou não softwares específicos, operamos um movimento de ida e vinda nas leituras, selecionando trechos e atribuindo notas breves (comentários ou lembretes) baseados em nossos "preconceitos", no sentido da pré compreensão assinalada por Gadamer ${ }^{29}$ (p. 68-70), e nos pressupostos teóricos e conceituais antes referidos, mas sempre com zelo para evitar etiquetas deterministas e simplistas, contrariando a natureza dialética do exercício pretendido:

El proceso analítico de escribir marcha paralelo al de leer.

Así como escribir es uma cto positivo para encontrar sentido, también lo es leer (o ló debería ser). Um acercamiento activo y de tipo analítico a la "literatura" es parte importante Del proceso recurrente de reflexión e interpretación 16 (p. 130).

Sendo nosso material básico de análise na $\mathrm{ACD}$, no contexto da avaliação em saúde, diferentes discursos (de atores) que se relacionam em determinado cenário de práxis, partimos de um olhar atento não somente à estrutura (ou seja às categorias que o compõem) mas aos distintos interesses em luta, no sentido da manutenção ou da transformação das distintas dimensões em jogo nas intervenções sob estudo, - seja uma política, um programa, um serviço, uma ação especifica.

O ponto de partida de nosso exercício hermenêutico são os eixos temáticos, ou seja, as dimensões interpretativas e as categorias preliminares baseadas na teoria, as quais vão sendo resignificadas e reelaboradas no processo de codificação, seguido da análise dos discursos, à medida que emergem categorias novas no campo investigativo. Os códigos frequentemente representam categorias de distintas abordagens, cujo esforço de síntese se inspira no pensar complexo. ${ }^{51}$ Algumas das quais já implicam referências interpretativas ao vincularem pressupostos teóricos e conceituais a questões críticas que emergem do campo de investigação.

Ao "lermos" essas categorias, vamos identificando as dimensões aludidas em modelos como o de Fairclough 35 (1991), identificando no discurso simultaneamente suas características textuais (como se estrutura? Quais categorias e temáticas? Quais lacunas e silêncios?), sua "função" como prática discursiva e também prática social. Ou seja, a dimensão propriamente política de cada discurso, com a ressalva de que as categorias discursivas, consideradas como estrutura em análises de discurso tradicionais, são também políticas, pois se inserem em códigos e derivam de lugares de fala específicos.

$\mathrm{O}$ processo de codificação realizado na $\mathrm{ACD}$ 
possibilita a identificação de fenômenos instigantes; os códigos, tomados como princípios organizadores do material empírico, favorecem ainda o reordenamento dos "dados", provocando-nos, consoante o círculo hermenêutico, a problematizá-los sob ângulos distintos, por vezes, distantes de nossas ideias de partida.

Nesse passo hermenêutico, ao longo do processo de codificação, operamos com um modelo que focaliza relações sistemáticas (ainda que abertas a novas construções) entre os eixos temáticos, dimensões analíticas e categorias discursivas presentes no material empírico - implicando em uma estratégia analítica, assumida como uma Rede Interpretativa:

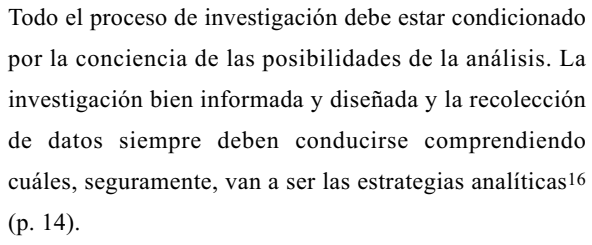

Procuramos evidenciar nos discursos analisados aqueles que se diferenciam por expressar opinião notoriamente inovadora e, por vezes, oposta às demais. É interessante verificar ao longo desse processo hermenêutico que várias das vozes e experiências nelas presentes produzem insights, surpresas e outros impactos de viva importância em nosso esforço compreensivo. Realizamos a condensação em unidades analisáveis - e o fazermos à semelhança da codificação descrita por Coffey e Atkinson 16 (p. 31-62) como o processo de compilação dos dados na perspectiva de expandir, transformar e recontextualizar os mesmos, ampliando assim as possibilidades analíticas no sentido de reconstruirmos diversas facetas das experiências dos beneficiários de programas ou usuários de serviços, sob forma de um texto analítico, intrinsecamente relacionado a um processo de teorização. Trabalho intelectual esse que, sabe-se, além de exigir uma leitura ativa da literatura, requer uma interação criativa e disciplinada com as informações qualitativas. Nesse prisma, a codificação foi empregada para interagir com os dados até alcançar categorias mais gerais e simples e, adicionalmente, selecionar e recombinar os dados com vistas à formulação de novas perguntas e níveis de interpretação.

Percorrendo e integrando os achados mediante o processo de codificação, criamos categorias com eles e a partir deles, estabelecendo vínculos em vários planos, destacando excertos significativos por nós reunidos para identificar, criativa e criticamente, categorias discursivas (excertos de falas transcritas) estreitamente relacionados às dimensões analíticas e eixos temáticos, sempre buscando unidades significativas, como parte do empreendimento indutivo guiado pelos objetivos traçados para a pesquisa.

\section{Considerações finais}

Em nossas incursões, mediante a ACD, no âmbito de estudos fundamentados no enfoque qualitativo de investigação em saúde, voltados a um amplo leque de fenômenos protagonizados por beneficiários, usuários, gestores, profissionais e outros segmentos envolvidos nessas pesquisas, operacionalizamos a análise dos diferentes corpus discursivos em termos do como eles se desenvolvem ou como se constroem sentidos e significados sobre as ações em saúde. Fundamentados pelas premissas hermenêuticas da $\mathrm{ACD}$, atentos, portanto, às confluências e, igualmente, aos paradoxos, contradições, silêncios, lacunas, torna-se possível problematizar e evidenciar a relação do sujeito com o sentido face à determinação histórica do processo de significação, estabelecidas as correlações entre fontes documentais, imagens, e situações narradas ou argumentos expressos pelos participantes.

Nesse exercício compreensivo, assentados na teoria crítica, muitas vezes se faz necessária a resignificação (ou mesmo mudanças) dos pressupostos teóricos e conceituais inicialmente demarcados, em um movimento dialógico permanente entre teoria e empiria, do qual emerge uma rede de significados (ou rede interpretativa), tecida num movimento recursivo, entre o dito, o não dito, as palavras, os gestos, o silêncio, as lacunas. Isso porque o esforço propriamente humano de compreender deve também partir da consideração de que sempre há algo no discurso ininteligível, quer seja em função da limitação do intérprete, de problemas da própria comunicação ou mesmo por conta de o sujeito que fala não saber precisar o que pretende dizer. Por evidente, em seu conjunto, dificuldades dessa natureza desafiam a análise contextualizada e situada da produção discursiva, para o que o aporte da vertente crítica é de importância capital, permitindo desvelar aspectos do discurso que permaneceriam de outro modo, velados, dentre eles, o vínculo sujeito-estrutura.

Conforme procuramos argumentar, a opção pela ACD na pesquisa em saúde implica uma mudança epistemológica radical em relação a uma análise que compreenda o discurso como mera estrutura, naturalizando-o. Conquanto apoiada na abertura hermenêutica às vivências e em uma postura reflexiva com esteio em uma abordagem críticocompreensiva na intertextualidade que se estabelece 
na situação de pesquisa, a ACD implica questionar os pressupostos e as maneiras como habitualmente damos sentido às coisas a partir de nosso lugar no mundo, como também exige um olhar atento, dialético, à realidade sensível (e singular) de cada discurso, bem como às particularidades percebidas em cada contexto no qual interagimos e no qual buscamos construir sentidos.

Por fim, entendendo o discurso como ação nas relações socialmente construídas, é pertinente analisar criticamente aqueles cenários expressos em diferentes arenas, dentre os quais se inclui a práxis na saúde, objeto primordial no âmbito das pesquisas qualitativas nesse campo da vida social. Mais que isso, categorias como equidade e humanização no cuidado à saúde, indissociavelmente relacionadas à integralidade das ações, dentre outras proposições, destacam-se como potencialmente capazes de articular estrutura e sujeito, sobretudo porque valora a ressignificação de práticas na dinâmica da expressão e articulação de princípios fundamentais e diretrizes programáticas do SUS. Sendo assim, e considerando

\section{Referências}

1. Cohn A. A reforma sanitária brasileira após 20 anos do SUS: reflexões. Cad Saúde Pública. 2009; 25 (7): 1614-9.

2. Bosi MLM, Mercado-Martinez FJ. Modelos avaliativos e reforma sanitária Brasileira: enfoque qualitativo-participativo. Rev Saúde Pública. 2010; 44 (3): 566-70.

3. Pires MRGM, Göttems LBD, Cupertino TV, Leite LS, Vale LR, Castro MA, Lage ACA, Mauro TGS. A utilização dos serviços de atenção básica e de urgência no SUS de Belo Horizonte: problema de saúde, procedimentos e escolha dos serviços. Saúde Soc. 2013; 22 (1): 211-22

4. Campos RO, Furtado J, Passos E, Benevides R. Pesquisa avaliativa em saúde mental: desenho participativo e efeitos da narratividade. São Paulo: Hucitec; 2008.

5. Campos RO, Furtado JP. Desafios da avaliação de programas e serviços em saúde. Campinas: Editora Unicamp; 2011.

6. Santos Filho SB. Avaliação e humanização em saúde. Ijuí: Editora Unijuí; 2009.

7. Pinheiro R, Martins PH. Avaliação em saúde na perspectiva do usuário: abordagem multicêntrica. Rio de Janeiro: CEPESC/IMS-UERJ; 2009.

8. Patton MQ. Qualitative research \& evaluation methods. 3 ed. London: Sage; 2002

9. Guba EG, Lincoln YS. Fourth generation evaluation. London: Sage; 1989

10. Uchimura KY, Bosi MLM. Qualidade e subjetividade na avaliação de programas e serviços em saúde. Cad Saúde Pública. 2002; 18 (6): 1561-9.

11. Guimaraes EAA, Carmo RF, Loyola Filho AI, Meira AJ, Luz ZMP. O contexto organizacional do Sistema de Informações sobre Nascidos Vivos segundo profissionais o contexto (em suas diferentes dimensões) e permanente movimento, bem como os discursos, expressos em documentos oficiais, nas redes sociais, na voz dos beneficiários, profissionais e outros atores, e em tantos outros materiais que constroem a empiria no enfoque qualitativo, sua análise não pode prescindir de uma fundamentação que considere a singularidade do processo de expressão comunicativa do sujeito historicamente situado.

\section{Agradecimentos}

À Fundação Cearense de Desenvolvimento Científico e Tecnológico (FUNCAP) pela outorga de bolsa de doutorado ao segundo autor e ao Conselho Nacional de Desenvolvimento Científico e Tecnológico ( $\mathrm{CNPq}$ ) pelo apoio financeiro e concessão de bolsas à linha de pesquisa coordenada pela primeira autora, junto à Pós Graduação em Saúde Coletiva da Universidade Federal do Ceará (UFC), iniciativas das quais derivam, dentre outros produtos, o presente artigo.

de saúde do nível municipal. Rev Bras Saúde Matern Infant. 2014; 14 (2): 165-72.

12. Jung SI, Serralta FB, Nunes MLT, Eizirik CL. Beginning and end of treatment of patients who dropped out of psychoanalytic psychotherapy. Trends Psychiatry Psychother. 2013; 35 (3): 181-90.

13. Martes ACB, Faleiros SM. Acesso dos imigrantes bolivianos aos serviços públicos de saúde na cidade de São Paulo. Saúde Soc. 2013; 22 (2): 351-64.

14. Bohman J. New philosophy of social sience: problems of Indeterminacy. Cambridge: MITPress; 1991.

15. Mercado-Martinez JM, Bosi MLM. Introdução: notas para um debate. In: Mercado JM, Bosi MLM (Orgs). Pesquisa qualitativa de serviços de saúde. 2 ed. Petrópolis: Vozes; 2007, p. 23-71.

16. Coffey A, Atkinson P. Encontrar el sentido a lós datos cualitativos: estratégias complementares de investigación. Medellín: Editorial Universidad de Antioquia; 2003.

17. Bourdieu P. Compreender. In: Bourdieu P (Coord.). A miséria do mundo. 8 ed. Petrópolis: Vozes; 2011, p. 693713.

18. Bosi MLM. Pesquisa qualitativa em saúde coletiva: panorama e desafios. Ciênc Saúde Coletiva. 2012; 17 (3): 575-86.

19. Paillé P, Mucchielli A. L'ánalyse qualitative en sciences humaines et sociales. 3 ed. Paris: Armand Colin; 2012.

20. Minayo MC, Assis SG, Souza ER (Orgs). Avaliação por triangulação de métodos: abordagem de programas sociais. Rio de Janeiro: Editora Fiocruz; 2005.

21. Santos BS. O discurso e o poder: ensaio sobre a sociologia da retórica jurídica. Porto Alegre: Fabris; 1998. 
22. Maldidier D, Normad C, Robin R. Discurso e ideologia: bases para uma pesquisa. In: Orlandi EP. Gestos de leitura. Campinas: Unicamp; 2010. p. 69-106.

23. Kuhn TS. A estrutura das revoluções científicas. 9 ed. Tradução de Beatriz Vianna Boeira e Nelson Boeira. São Paulo: Perspectiva; 2009.

24. Heidegger M. Ser e tempo. Tradução de Márcia de Sá Cavalcante. Petrópolis: Vozes; 1993

25. Dilthey W. A construção humana do mundo histórico nas ciências humanas. Tradução de Marco Antônio Casanova. São Paulo: Unesp; 2010.

26. Lüdke M, André MEDA. Pesquisa em educação: abordagens qualitativas. 2 ed. São Paulo: Epu; 1986.

27. Gracia TI. O "giro lingüístico”. In: Iñiguez L (Coord.) Manual de análise do discurso em ciências sociais Tradução de Vera Lúcia Joscelyne. Petrópolis: Vozes; 2004. p. 19-49.

28. Orlandi EP. Análise de discurso: princípios e procedimentos. Campinas: Pontes; 2012.

29. Gadamer HG, Fruchon P (Org.). O problema da consciência histórica. Tradução de Paulo César Duque Estrada. 3. ed Rio de Janeiro: Editora FGV; 2009.

30. Bouveresse J. Prodígios y vértigos de la analogía: sobre o abuso de la literatura em el pensamiento. 2 ed. Traduzido por Helena Alapin. Buenos Aires: Libros del Zorzal; 2005.

31. Demo P. Pesquisa e informação qualitativa. 4 ed. Campinas: Papirus; 2009.

32. Palassi MP, Carrieri AP, Leite-da-Silva AR, Pimentel TD Os discursos e as metáforas na análise da propensão à participação: um estudo em um banco privatizado. Rev Adm Pública. 2007; 41 (3): 443-73.

33. Wiklund L, Lindholm L, Lindström, UA. Hermeneutics and narration: a way to deal with qualitative data. NursingInquiry 2002; 9 (2): 114-25.

33. Durán CR. Não pense, sinta! O sensacionismo de Fernando Pessoa. Revista Pessoa 2010. [Internet]. [acesso em 18 ago 2014]. Disponível em: http://www.revistapessoa.com

34. Thompson JB. Ideologia e cultura moderna: teoria social crítica na era dos meios de comunicação de massa. 8 ed. Tradução de Carmen Grisci e outros. Petrópolis: Vozes; 2009.

35. Fairclough N. Discurso e mudança social. Tradução de Izabel Magalhães, et al. Brasília: Editora UNB; 1991
36. Fairclough N. Critical and descriptive goals in discourse analysis. J Pragmatics. 1985; 9: 739-63.

37. Melo Neto JC. A educação pela pedra. Rio de Janeiro: Alfaguara Brasil; 2008. Disponível em: http://pt.scribd.com /doc/61605099/1966-2008-A-Educacao-pela-Pedra-JoaoCabral-de-Melo-Neto

38. Pêcheux M. Análise automática do discurso (AAD-69). In: Gadet F, Hak T (Orgs). Por uma análise automática do discurso: uma introdução às obras de Michel Pêcheux. Campinas: Editora Unicamp; 1997

39. Pêcheux M. Analyse de contenu et théorie du discours. Bulletin du CERP. 1967; 16 (3): 211-27.

40. Pêcheux M. Vers une technique d'analyse du discours. Psychologie Française. 1968; 13 (1): 113-7.

41. Melo IF. Análise do discurso e análise crítica do discurso: desdobramentos e intersecções. Letra Magna. 2009; 1 (11): $1-2$.

42. Tílio R. Revisitando a análise crítica do discurso: um instrumental teórico-metodológico. Rev Curso de letras da UNIABEU. 2010; 1 (2): 86-102.

43. Guimarães CP. análise crítica do discurso: reflexões sobre contexto em Van Dijk e Fairclough. Rev Eutomia. 2012; 2: 438-57.

44. Dijk TAV. El análisis crítico del discurso. Anthropos. 1999; 186: 23-36.

45. Wodak R. What CDA isabout In: Wodak R, Meyer M (Orgs). Methods of critical discourse analysis. London: Sage; 2001. p. 121-38.

46. Pêcheux M. Semâtica e discurso: uma crítica à afirmação do óbvio. Tradução de Eni Puccinelli Orlandi, et al. 4 ed. Campinas: Editora Unicamp; 2009.

47. Kosik K. Dialética do concreto. 7 ed. Tradução de Célia Beves e Aderico Tóribio. Rio de Janeiro: Paz e Terra; 2002.

48. Gramsci A. Concepção dialética da história. 9 ed. Tradução de Carlos Nelson Coutinho. Rio de Janeiro: Civilização Brasileira; 1976.

49. Santos BS. A crítica da razão indolente: contra o desperdício da experiência. São Paulo: Cortez; 2006.

50. Foucault M. Microfísica do poder. Tradução de Roberto Machado. 26 ed. Rio de Janeiro: Graal; 2008.

51. Morin E. O problema epistemológico da complexidade. Porto: Europa-America; 1996

Recebido em 19 de junho de 2014

Versão final apresentada em 25 de agosto de 2014

Aprovado em 15 de setembro de 2014 